\title{
Outcomes Frequently Specified in Cochrane Reviews of Community-based Psychosocial Interventions for Adults with Severe Mental Illness: A Systematic Search and Narrative Synthesis
}

\section{Momoka Igarashi ( $\nabla$ igarashi@ncnp.go.jp)}

National Center of Neurology and Psychiatry https://orcid.org/0000-0003-4352-3365

\section{Sosei Yamaguchi}

National Center of Neurology and Psychiatry: Kokuritsu Seishin Shinkei Center

\section{Takayuki Kawaguchi}

National Center of Neurology and Psychiatry: Kokuritsu Seishin Shinkei Center

\section{Makoto Ogawa}

National Center of Neurology and Psychiatry: Kokuritsu Seishin Shinkei Center

\section{Sayaka Sato}

National Center of Neurology and Psychiatry: Kokuritsu Seishin Shinkei Center

Chiyo Fujii

National Center of Neurology and Psychiatry: Kokuritsu Seishin Shinkei Center

\section{Short report}

Keywords: Psychosocial interventions, Outcome selection, Cochrane review, Community mental health, Severe mental illness

Posted Date: June 24th, 2021

DOI: https://doi.org/10.21203/rs.3.rs-629730/v1

License: (9) This work is licensed under a Creative Commons Attribution 4.0 International License. Read Full License

Version of Record: A version of this preprint was published at Neuropsychopharmacology Reports on November 1st, 2021. See the published version at https://doi.org/10.1002/npr2.12216. 


\section{Abstract}

Background: Outcome selection in intervention studies is a critical issue for synthesising evidence. This study is aimed to investigate outcomes used in Cochrane reviews assessing community-based psychosocial interventions for adults with severe mental illness.

Methods: Cochrane reviews that evaluated a community-based psychosocial intervention for adults with severe mental illness were searched electronically and manually. We extracted all outcomes specified in the Methods section in each Cochrane review. Outcomes that represent the same concept and context were synthesised into an outcome term. Outcome terms were categorised according to the existing taxonomy.

Results: We included 31 Cochrane reviews. Of the 214 outcome terms identified, 13 were used in more than half of the reviews: quality of life, mental state, economic outcome, admission to hospital, leaving the study early, social functioning, satisfaction, global state, relapse, adverse events/effects, carer satisfaction, employment, duration of admission. Most outcome terms were categorised into the life impact core area $(57 \%)$, followed by the resource use area (21\%).

Conclusions: Our study provides a candidate outcome list for developing a core outcome set for severe mental illness and offers a basis for comparison for future outcome investigation on mental health research.

\section{Background}

Measuring identical outcomes in clinical trials has become important internationally to synthesise evidence and achieve better health and social care [1,2]. This global trend has accelerated the development of core outcome sets (COSs) in the field of mental health [3-5]. Currently, there are no consensus outcome sets for evaluating community-based psychosocial interventions for people with severe mental illness, including schizophrenia.

Community-based psychosocial interventions cover various diagnoses rather than one specific diagnosis, and include a wide variety of approaches such as assertive community treatment, supported employment, and cognitive behavioural therapy [6]. Despite the variety of diagnoses and interventions, there are two reasons to develop COSs for community-based psychosocial interventions for people with severe mental illness. First, although their diagnoses differ, such individuals appear to have common needs and goals regarding living in the community despite serious functional impairment [7, 8]. An outcome set that corresponds to common needs and goals would help researchers focus not just on alleviating symptoms specific to each disease, but also on people's problems and concerns in everyday life and their expectations concerning community mental health services. Second, there should be one outcome set that can be used to evaluate various interventions to assess how effectively each intervention achieves the end goal. People who use several types of community service may not necessarily have a completely different purpose for each service. It would be beneficial to define 
important outcomes independently of specific interventions in order to highlight the ultimate goals of people with severe mental illness.

COSs are generally developed through multiple steps. Researchers first create a long list of potentially essential outcomes by reviewing relevant studies and performing qualitative surveys of stakeholders, while also collaborating with service users [2]. The purpose of assessing previous studies is to identify outcomes that have been commonly reported. An effective approach is to examine the outcomes used in relevant Cochrane reviews, which provide high-quality evidence and have international influence [9]. However, no studies have reported the results of this approach. We thus examined outcomes and their frequencies in Cochrane reviews of community-based psychosocial interventions for people with severe mental illness. Identifying outcomes in Cochrane reviews can contribute to developing a long list of outcomes for future COS studies in this area and help researchers select outcomes when they conduct clinical trials.

\section{Methods}

Cochrane reviews were searched electronically and manually. The electronic search was performed using the Cochrane library database with relevant keywords (see Additional file 1; Table 1). Cochrane reviews were eligible if they evaluated a community-based psychosocial intervention for adults with severe mental illness (i.e., schizophrenia, psychosis, bipolar disorder, or major depressive disorder). Studies were excluded if they met any of the following criteria: i) the intervention involved medication only or was implemented only in inpatient settings; ii) the participants were mainly children, adolescents, elderly people, or families of patients; and iii) the participants had postnatal or prodromal psychosis. We excluded children, adolescents, and elderly people since they are likely to have developmentally specific goals and needs that are qualitatively different from those of adults with severe mental illness. We also searched the Cochrane library manually using the keyword "severe/serious mental illness", and obtained reviews that seemed to meet our criteria. Title and abstract screening and full-text screening were independently completed by two authors (MI and SY). Any identified discrepancies were resolved through discussion with a co-author (CF).

For each Cochrane review, we extracted all outcomes specified in the Methods section. More specifically, we identified outcomes that indicated what factor was measured rather than those describing how it was measured. For example, we extracted only "general behaviour" from "no clinically important change in general behaviour". Composite outcomes (e.g., "quality of life/treatment satisfaction") were divided into two or more outcomes, as appropriate (e.g., "quality of life" and "treatment satisfaction"). We did not distinguish whether outcomes were originally classified as primary or secondary. In Cochrane reviews, outcomes are categorised as headings, which refer to outcomes in a broad sense, or as subheadings, which refer either to outcomes in a narrow sense or to how the outcomes are measured. Outcomes were extracted regardless of whether they were categorised as headings or as subheadings. An identical outcome was extracted only once from a single review. One author (MI) extracted outcomes and another author (TK) checked whether the outcome extraction was correct. 
We synthesised outcomes according to the definition of "unique outcomes" by Young et al. [10], which indicates that outcomes with different words, phrasing, or spelling that represent the same concept and context are recognised as one outcome. For example, "length of hospital stay" and "duration of admission" were combined as one outcome, namely "duration of admission". An outcome indicating the number of participants who met a condition (e.g., "number of participants admitted to hospital") was considered to be the same as an outcome indicating the proportion of participants (e.g., "admission to hospital"). When there was a broader outcome (e.g., "mental state") and a narrower outcome (e.g., "positive symptoms"), the narrower one was not included in the broader one but was organised separately. Outcome categorisation was conducted according to the taxonomy developed by Dodd et al [11]. Additional subdomains were created if appropriate. Outcomes were synthesised and categorised based on discussion among the four authors, one of whom was a user researcher ( $\mathrm{MI}, \mathrm{SY}, \mathrm{TK}$, and MO).

\section{Results}

Electronic and manual searches identified 108 and 10 Cochrane reviews, respectively. Of these, 31 Cochrane reviews were included (see Additional file 1; Fig. 1, Table 2). The year of publication ranged from 2001 to 2019. A total of 954 outcomes were initially extracted. The number of outcomes per review ranged from 6 to 54 (median 33; interquartile range 10). After integrating outcomes with the same wording, the number of outcomes was 475 . These were synthesised into 214 unique outcome terms (see Additional file 2).

Thirteen outcome terms (6\%) were specified in more than half of the reviews (Table 1). Six of the 13 outcome terms were categorised into the life impact area. On the other hand, nearly half $(n=99,46 \%)$ of the outcome terms were specified in only one review, and three quarters $(n=160,75 \%)$ were specified in three or fewer reviews. 
Table 1

Outcome terms specified in more than half of the included Cochrane reviews

\begin{tabular}{|llrll|}
\hline Outcome term & $\begin{array}{l}\text { Number of Cochrane reviews which specified } \\
\text { the outcome term }\end{array}$ & $\%$ & Core area \\
\hline Quality of life & 28 & 90.3 & Life impact \\
\hline Mental state & 27 & 87.1 & Physiological/clinical \\
$\begin{array}{l}\text { Economic } \\
\text { outcome }\end{array}$ & 27 & 87.1 & Resource use \\
\hline $\begin{array}{l}\text { Admission to } \\
\text { hospital }\end{array}$ & 27 & 87.1 & Resource use \\
\hline $\begin{array}{l}\text { Leaving the study } \\
\text { early }\end{array}$ & 25 & 80.6 & Life impact \\
\hline $\begin{array}{l}\text { Social } \\
\text { functioning }\end{array}$ & 24 & 77.4 & Life impact \\
\hline $\begin{array}{l}\text { Satisfaction } \\
\text { Global state }\end{array}$ & 24 & 77.4 & Life impact \\
\hline Relapse & 22 & 74.2 & NA \\
\hline $\begin{array}{l}\text { Adverse } \\
\text { events/effects }\end{array}$ & 19 & 71.0 & Physiological/clinical \\
\hline $\begin{array}{l}\text { Carer satisfaction } \\
\text { Employment }\end{array}$ & 17 & 61.3 & Adverse \\
\hline $\begin{array}{l}\text { Duration of } \\
\text { admission }\end{array}$ & 16 & 54.8 & Life impact \\
\hline
\end{tabular}

The outcome terms were categorised into five core areas with 38 outcome domains according to Dodd et al. [11]. The life impact area included the largest number of outcome terms $(n=118,55 \%)$; these involved aspects of functioning or satisfaction in real life, such as physical/social/role/emotional/cognitive functioning, quality of life, and satisfaction with services. All 31 reviews specified more than one life impact outcome term. The other core areas were death $(n=4,2 \%)$, physiological/clinical $(n=40,19 \%)$, resource use $(n=45,21 \%)$, and adverse events/effects $(n=4,2 \%)$. The three most frequently specified domains were delivery of care $(n=29$; life impact), psychiatric outcomes $(n=23$; physiological/clinical), and hospital/service use $(n=23$; resource use). Four outcome terms (global state, behaviour, specific behaviour, and general functioning) could not be categorised into any domain because their concepts are unspecific.

\section{Discussion}


In this study, 13 outcome terms were specified in more than half of the reviews. This is highly consistent with the report of Wuytack et al. [12], which found that nine outcomes were used in more than half of the 10 Cochrane reviews published by the Cochrane schizophrenia group in 2013. Seven outcomes were included in both studies: quality of life, mental state, economic outcomes, leaving the study early, social functioning, satisfaction, and adverse events/effects. On the other hand, six of our 13 frequently specified outcome terms were not among the nine outcomes identified by Wuytack et al. In particular, career satisfaction and employment may reflect the characteristics of our target population, as its members are likely to live with careers or intend to get a job in the community.

Adverse events/effects and economic outcomes might have ranked high because this study investigated the outcomes of Cochrane reviews. The Cochrane Handbook of Systematic Reviews of Healthcare Interventions suggests that every healthcare intervention comes with some risk of harmful or adverse events/effects, and recommends that all Cochrane reviews try to include some consideration of the adverse aspects of the interventions [13]. Economic perspectives are also recognised as useful in Cochrane reviews, in order to build evidence on the cost-effectiveness of optimal healthcare decisionmaking [14]. Our results confirmed that Cochrane reviews emphasise the importance of the feasibility and safety of interventions by assessing adverse events/effects and economic outcomes.

In terms of outcome categorisation, the life impact area included the majority of outcomes $(n=118,55 \%)$ in this study. Six of the 13 most frequently specified outcome terms were also in the life impact area. These results differ from those of a previous study that categorised outcomes reported in clinical trials of adolescent major depressive disorder [15]. In that study, the majority of outcomes (62\%) were in the physiological/clinical area, while only a relatively small number $(27 \%)$ were classified into the life impact area. This difference in proportion implies that researchers who evaluate interventions for severe mental illness in community settings are more interested in outcomes related to various aspects of patients' functioning or satisfaction in life than in clinical indicators.

Our study is the first to comprehensively investigate the outcomes specified in Cochrane reviews of community-based psychosocial interventions for people with severe mental illness, and to report these outcomes along with their frequencies. Since Cochrane reviews are internationally influential systematic reviews [9], the outcome data used by Cochrane review authors impact future randomised controlled trials (RCTs) and systematic reviews. They also offer a basis for comparing future outcome studies that investigate outcomes used in studies of other designs (such as RCTs or systematic reviews other than Cochrane reviews), mental illnesses, or populations.

A particularly important contribution of our study is that it provides a list of candidate outcomes for the development of a COS for community-based interventions for severe mental illness. Collecting potential outcomes by reviewing previous studies is an essential step in COS development. An organised outcome list with a well-documented creation process can be a promising tool to develop a COS for people in the community with severe mental illness. Note that we do not insist that researchers use the popular outcomes in Cochrane reviews for intervention studies. Our list of outcomes may be used in the initial 
stage of COS development, but the following stages need to include patients and other stakeholders to build a consensus on outcomes that should be assessed in intervention studies.

\section{Limitations}

This study focused only on the methods sections of Cochrane reviews and did not examine the results sections. To determine what outcomes are of interest to researchers conducting RCTs, future studies may need to assess the outcomes reported by individual RCTs.

\section{Conclusions}

Our comprehensive list of outcomes in Cochrane reviews can be used as a candidate outcome list for developing a COS for people in the community with severe mental illness. Future COS development should synthesize patients' and other stakeholders' views with scientific accumulation, such as our list, to build a consensus on important outcomes in this area.

\section{Declarations}

\section{Ethics approval and consent to participate}

Not applicable.

\section{Consent for publication}

Not applicable.

\section{Availability of data and materials}

The datasets used and/or analysed during the current study are available from the corresponding author on reasonable request.

\section{Competing interests}

The authors declare that they have no competing interests.

\section{Funding}

This work is supported by a research grant from National Center of Neurology and Psychiatry (No. 1-3: Fundamental Study on Effective Community Services for People with Severe Mental Disorders and Their Families) and by a Health and Labour Sciences Research Grant from the Ministry of Health, Labour and Welfare (19189500: Development of a Website as the Platform for Gathering Evidence on Mental Health and Welfare and Outcomes of Long-term Psychiatric Patients After Discharge to Communities). The funders did not have a role in the design of the study and collection, analysis, and interpretation of data and in writing the manuscript. 


\section{Authors' contributions}

$\mathrm{MI}$ led the analysis and interpretation of data and drafted the first version of the manuscript. SY designed the study concept, contributed to the analysis and interpretation of data, and supervised the entire process. TK contributed to the analysis and interpretation of data. MO and CF contributed to the interpretation of data. SS helped search for Cochrane reviews by hand. All authors critically revised the manuscript and approved the final version of the manuscript. Other contributions are stated within the article.

\section{Acknowledgements}

Not applicable.

\section{References}

1. Williamson P, Altman D, Blazeby J, Clarke M, Gargon E. Driving up the quality and relevance of research through the use of agreed core outcomes. J Health Serv Res Policy. 2012;17(1):1-2.

2. Williamson PR, Altman DG, Bagley H, Barnes KL, Blazeby JM, Brookes ST, et al. The COMET Handbook: version 1.0. Trials. 2017;18(suppl 3):280.

3. Tyler N, Wright N, Grundy A, Waring J. Developing a core outcome set for interventions to improve discharge from mental health inpatient services: a survey, Delphi and consensus meeting with key stakeholder groups. BMJ Open. 2020;10(5):e034215.

4. Taylor J, Böhnke JR, Wright J, Kellar I, Alderson SL, Hughes T, et al. A core outcome set for evaluating self-management interventions in people with comorbid diabetes and severe mental illness: study protocol for a modified Delphi study and systematic review. Trials. 2017;18(1):70.

5. Retzer A, Sayers R, Pinfold V, Gibson J, Keeley T, Taylor G, et al. Development of a core outcome set for use in community-based bipolar trials-A qualitative study and modified Delphi. PLoS One. 2020;15(10):e0240518.

6. Dixon LB, Dickerson F, Bellack AS, Bennett M, Dickinson D, Goldberg RW, et al. The 2009 schizophrenia PORT psychosocial treatment recommendations and summary statements. Schizophr Bull. 2010;36(1):48-70.

7. Miyamoto Y, Hashimoto-Koichi R, Akiyama M, Takamura S. Mental health and social service needs for mental health service users in Japan: a cross-sectional survey of client- and staff-perceived needs. Int J Ment Health Syst. 2015;9:19.

8. Drake RE, Whitley R. Recovery and Severe Mental Illness: Description and Analysis. The Canadian Journal of Psychiatry. 2014;59(5):236-42. 
9. Bunn F, Trivedi D, Alderson P, Hamilton L, Martin A, Pinkney E, et al. The impact of Cochrane Reviews: a mixed-methods evaluation of outputs from Cochrane Review Groups supported by the National Institute for Health Research. Southampton (UK): NIHR Journals Library; 2015.

10. Young AE, Brookes ST, Avery KNL, Davies A, Metcalfe C, Blazeby JM. A systematic review of core outcome set development studies demonstrates difficulties in defining unique outcomes. J Clin Epidemiol. 2019;115:14-24.

11. Dodd S, Clarke M, Becker L, Mavergames C, Fish R, Williamson PR. A taxonomy has been developed for outcomes in medical research to help improve knowledge discovery. J Clin Epidemiol. 2018;96:84-92.

12. Wuytack F, Smith V, Clarke M, Williamson P, Gargon E. Towards core outcome set (COS) development: a follow-up descriptive survey of outcomes in Cochrane reviews. Systematic reviews. 2015;4:73.

13. Peryer G, Golder S, Junqueira D, Vohra S, Loke YK. Chapter 19: Adverse effects. In: Cochrane Handbook for Systematic Reviews of Interventions version 6.2 (updated February 2021). Cochrane. 2021. https://training.cochrane.org/handbook/current/chapter-19. Accessed 18 May 2021.

14. Aluko P, Graybill E, Craig D, Henderson C, Drummond M, Wilson ECF, et al. Chapter 20: Economic evidence. In: Cochrane Handbook for Systematic Reviews of Interventions version 6.2 (updated February 2021). Cochrane. 2021. https://training.cochrane.org/handbook/current/chapter-20. Accessed 18 May 2021.

15. Mew EJ, Monsour A, Saeed L, Santos L, Patel S, Courtney DB, et al. Systematic scoping review identifies heterogeneity in outcomes measured in adolescent depression clinical trials. $\mathrm{J}$ Clin Epidemiol. 2020;126:71-79.

\section{Supplementary Files}

This is a list of supplementary files associated with this preprint. Click to download.

- Additionalfile1.docx

- Additionalfile2.xlsx 